\title{
Trajetória formativa dos educadores de jovens e adultos: o estado do conhecimento
}

\section{Formative trajectory of youth and adult educators: the state of knowledge}

\author{
Trayectoria formativa de educadores de jóvenes y \\ adultos: el estado del conocimiento
}

\author{
Marileide Lima Moutinho Pamponet Lima ${ }^{1}$ \\ Adenilson Souza Cunha Júnior ${ }^{1}$
}

DOI: http://dx.doi.org/10.20435/serie-estudos.v26i56.1429

\begin{abstract}
Resumo: O artigo apresenta uma análise acerca das produções acadêmicas no âmbito de mestrado e doutorado no que diz respeito à formação docente dos educadores de jovens e adultos. Partindo da constatação de que o desenvolvimento profissional docente voltado para o público da Educação de Jovens e Adultos (EJA) vem acontecendo de uma maneira espontânea, "nas fronteiras", em que, no Brasil, não existe um perfil de educador de jovens e adultos, nem um parâmetro específico de formação destes educadores, fomos instigados a pesquisar o que tem sido produzido nessa temática, objetivando entender os processos formativos da EJA, bem como as realidades, possibilidades e dificuldades encontradas pelos professores dessa modalidade de ensino. Para tanto, lançamos o desafio de realizar uma pesquisa bibliográfica do tipo estado do conhecimento, com o recorte temporal de dez anos (2008-2018), utilizando os bancos digitais do Catálogo de Teses e Dissertações da Coordenação de Aperfeiçoamento de Pessoal de Nível Superior (CAPES), do Instituto Brasileiro de Informação em Ciência e Tecnologia (IBICT), dos anais das reuniões da Associação Nacional de Pós-Graduação e Pesquisa em Educação (ANPED) e dos Simpósios da Associação Nacional de Política e Administração da Educação (ANPAE). O trabalho em tela retrata uma investida exploratória, em teses e dissertações e trabalhos apresentados em eventos, resultando numa pesquisa quantitativa com recorte temporal, analisando como estão os estudos acerca da temática citada anteriormente.
\end{abstract}

Palavras-chave: trajetória formativa; Educação de Jovens e Adultos (EJA); estado do conhecimento.

Abstract: The article presents an analysis of academic productions under master and doctorate concerning the formative path of youth and adult educators. Based on the observation that professional teacher training aimed at the Youth and Adult Education (EJA) public has been happening spontaneously, "at the borders", in which, in Brazil, there is no profile of youth and

${ }^{1}$ Universidade Estadual do Sudoeste da Bahia (UESB), Itapetinga, Bahia, Brasil. 
adult educators, nor a training parameter for these educators, we were encouraged to research what has been produced in this theme, aiming to understand the training processes of Youth and Adult Education, as well as the realities, possibilities, and difficulties encountered by teachers in this type of teaching. To this end, we launched the challenge of conducting bibliographic methodological research called: state of knowledge, with the time frame of ten years (2008-2018), through the Periodic Banks of the Catalog of Theses and Dissertations of the Coordination for the Improvement of Higher Degree Personnel (CAPES) and Brazilian Institute of Information in Science and Technology (IBICT), annals of the National Association of Graduate Studies and Research in Education (ANPED), and publications of Symposia of the National Association for Education Policy and Administration (ANPAE). The work depicts an informative search, in theses dissertations and works, resulting in quantitative research with a time frame, analyzing how the studies on the theme mentioned above are.

Keywords: Formative Path. Youth and Adult Education (EJA). Systematization of knowledge.

Resumen: El artículo presenta un análisis de producciones académicas dentro del alcance del máster y doctorado con respecto a la trayectoria formativa de los educadores de jóvenes y adultos. Partiendo de la constatación de que la formación profesional de docentes dirigida al público de la Educación de Jóvenes y Adultos (EJA) se realiza de forma espontánea, "en las fronteras", en que, en Brasil, no existe un perfil de educadores de jóvenes y adultos, ni un parámetro de formación de educadores, nosotros fuimos instigados a investigar lo que se ha producido en esta temática, con el objetivo de comprender los procesos de capacitación de EJA, así como las realidades, posibilidades y dificultades que enfrentan los docentes en esta forma de enseñanza. Con este fin, lanzamos el desafío de llevar a cabo una investigación metodológica bibliográfica llamada estado del conocimiento, con un retorno de diez años (2008-2018), a través de los bancos periódicos del Catálogo de Tesis y Disertaciones de la Coordinación para el Mejoramiento del Personal de Educación Superior (CAPES) y el Instituto Brasileño de Información en Ciencia y Tecnología (IBICT), Actas de la Asociación Nacional de Estudios de Posgrado e Investigación en Educación (ANPED) y publicaciones de Simposios de la Asociación Nacional de Política y Administración de Educación (ANPAE). El trabajo en la pantalla retrata una investigación exploratoria, en tesis y disertaciones y trabajos, que resulta en una investigación cuantitativa con un marco de tiempo, analizando cómo son los estudios sobre la temática mencionada anteriormente.

Palabras clave: trayectoria formativa; Educación de Jóvenes y Adultos (EJA); estado del conocimiento.

\section{INTRODUÇÃO}

Este estudo é parte integrante de uma pesquisa de mestrado no Programa de Pós-Graduação em Educação (PPGED) da Universidade Estadual do Sudoeste da Bahia (UESB), que tem por objetivo principal analisar a trajetória formativa do educador de jovens e adultos no médio sudoeste da Bahia.

A escolha da temática parte da constatação de uma vivência profissional da autora enquanto docente da Educação de Jovens e Adultos (EJA), quando foi 
possível observar o fato de ser recorrente certa dificuldade quanto ao desenvolvimento profissional docente de atividades pedagógicas na modalidade de ensino EJA.

Para o desenvolvimento deste artigo, apresentaremos resultados levantados, de como andam as pesquisas sobre formação docente do educador de jovens e adultos. Elas serão identificadas a partir dos seguintes descritores de busca: "formação docente do educador de EJA"; "atuação docente na EJA"; "políticas educacionais para Educação de Jovens e Adultos (EJA)".

Os descritores foram definidos a partir de uma análise feita no projeto de pesquisa, e estes apresentados no parágrafo anterior foram os que melhor satisfizeram às necessidades semânticas da área e às especificidades da Educação de Jovens e Adultos no âmbito da pesquisa da autora.

O trabalho do tipo estado do conhecimento ${ }^{2}$, adotado nesta etapa, apresenta um caráter bibliográfico quantitativo e tem sua relevância como pesquisa, pois permite o contato do pesquisador com as produções existentes quanto à temática analisada, evitando, assim, que se incorra no erro de repetir aquelas já anteriormente realizadas e possibilitando, também, uma melhor percepção acerca das lacunas relacionadas ao conhecimento sobre o tema. Soares (1989) aponta outras vantagens, informando que o estado do conhecimento:

É necessário no processo de evolução da ciência, a fim de que se ordene periodicamente o conjunto de informações e resultados já obtidos, ordenação que permita indicação das possibilidades de integração de diferentes perspectivas, aparentemente autônomas, a identificação de duplicações ou contradições, e a determinação de lacunas e vieses. (SOARES, 1989, p. 3).

Com o objetivo de mapear a quantidade de trabalhos de pós-graduação no campo de formação docente e das políticas públicas voltadas para a modalidade

\footnotetext{
2 Estado do conhecimento ou estado da arte, como é comumente chamado, é uma denominação utilizada no campo educacional, ou, como denominado na área de saúde, uma revisão narrativa (ELIAS et al. 2012), permitindo ao pesquisador estabelecer relações com produções anteriores, podendo assim identificar temáticas recorrentes na perspectiva de consolidação de uma área de conhecimento e constituindo-se em orientações de práticas pedagógicas para estudos de revisão bibliográfica. Nesse tipo de estudo, são analisadas as produções bibliográficas em "determinada área [...] fornecendo o estado do conhecimento sobre um tópico específico, evidenciando novas ideias, métodos, subtemas que têm recebido maior ou menor ênfase na literatura selecionada" (NORONHA; FERREIRA, 2000 apud VOSGERAU; ROMANOWSKI, 2014).
} 
de ensino EJA, realizou-se, num primeiro momento, uma pesquisa sem recorte temporal; porém, ao fazer uma análise mais detalhada, optou-se pelo recorte temporal compreendido entre os anos de 2008 e 2018.

A escolha referente à década para coleta de dados do estado do conhecimento se deu pelo fato de ser um período em que as discussões em torno das expressões das questões sociais e das políticas educacionais assumiram grandes proporções no Brasil; a EJA se efetivou de maneira mais consistente, como vinha sendo pretendida, desde a década de 1930, e, também, em virtude do tempo em que a autora teve o primeiro contato com a Pedagogia na área da Educação de Jovens e Adultos.

A pesquisa compreendeu trabalhos que abordam as concepções, metodologias e práticas da EJA, envolvendo questões relativas à formação dos educadores, à atuação docente e às políticas públicas voltadas para essa modalidade de ensino. Como a EJA frequentemente reconhece o educando enquanto trabalhador e remete às relações com o mundo do trabalho, foram considerados também estudos relacionados a essa temática.

Partindo deste ponto de vista, buscamos, por meio deste estudo, estabelecer um elo entre o conhecimento posto e aquele que ainda não foi produzido, o qual, por sua vez, torna-se necessário para sistematizar um determinado campo de conhecimento, reconhecendo os principais resultados da investigação, identificando temáticas, abordagens dominantes e emergentes, bem como lacunas e campos inexplorados abertos à pesquisa futura.

Para efeito de organização deste artigo, apresentaremos, numa primeira etapa, os dados quantitativos dos descritores desta pesquisa e, em seguida, faremos uma discussão com as informações importantes levantadas sobre o tema nos textos selecionados para análise.

Ao apresentarmos os dvescritores a seguir, faz-se necessário esclarecer que, no Catálogo de Teses e Dissertações da Coordenação de Aperfeiçoamento de Pessoal de Nível Superior (CAPES), foram aplicados os seguintes filtros: tipo (mestrado e doutorado); ano (2008-2018); grande área de conhecimento (Ciências Humanas); área de conhecimento (Educação de Adultos); área de avaliação e área de concentração (Educação). Já na busca avançada na Biblioteca Digital Brasileira de Teses e Dissertações (BDTD) e no Instituto Brasileiro de Informação em Ciência e Tecnologia (IBICT), a pesquisa foi refinada a partir da aplicação dos seguintes filtros: programa (pós-graduação em Educação); tipo (dissertação e tese); assunto 
(Educação de Jovens e Adultos); área de conhecimento (Ciências Humanas) e ano de defesa (2008-2018). E, por sua vez, fica claro que fora utilizada a mesma metodologia de pesquisa na CAPES. Assim, as tabelas a seguir, separadas por descritor, mostram o quantitativo das produções encontradas nos bancos de pesquisa mencionados anteriormente.

\section{FORMAÇÃO DOCENTE DO EDUCADOR DE JOVENS E ADULTOS: LEVANTAMENTO QUANTITATIVO}

Quadro 1 - Formação docente do educador de jovens e adultos

\begin{tabular}{|c|c|c|c|c|}
\hline \multicolumn{5}{|c|}{ FORMAÇÃO DOCENTE DO EDUCADOR DE JOVENS E ADULTOS } \\
\hline DESCRITORES CAPES & Dissertação & Tese & Total & Relação/tema \\
\hline $\begin{array}{l}\text { "Formação docente do educador de } \\
\text { jovens e adultos" }\end{array}$ & 53 & 33 & 86 & 05 \\
\hline $\begin{array}{l}\text { "Formação docente" AND } \\
\text { "Educação de Jovens e Adultos" }\end{array}$ & 35 & 08 & 43 & 08 \\
\hline DESCRITORES IBICT & Dissertação & Tese & Total & Relação/tema \\
\hline $\begin{array}{l}\text { "Formação docente" + "Educação de } \\
\text { Jovens e Adultos" }\end{array}$ & 45 & 18 & 63 & 02 \\
\hline $\begin{array}{c}\text { "Formação docente" "Educador de } \\
\text { Jovens e Adultos" }\end{array}$ & 25 & 09 & 34 & 05 \\
\hline
\end{tabular}

Fonte: dados coletados no Banco de Teses e Dissertações da CAPES e IBICT, jan./2020. Elaboração dos autores.

\subsection{Atuação docente na educação de jovens e adultos: levantamento quantitativo}

Quadro 2 - Atuação docente na EJA/Jovens e Adultos

\begin{tabular}{|c|c|c|c|c|}
\hline \multicolumn{5}{|c|}{ ATUAÇÃO DOCENTE NA EDUCAÇÃO DE JOVENS E ADULTOS } \\
\hline DESCRITORES CAPES & Dissertação & Tese & Total & Relação/tema \\
\hline $\begin{array}{c}\text { "Atuação docente na Educação de } \\
\text { Jovens e Adultos" }\end{array}$ & 54 & 33 & 87 & 03 \\
\hline $\begin{array}{l}\text { "Atuação docente" AND "Educação } \\
\text { de Jovens e Adultos" }\end{array}$ & 12 & 05 & 17 & 03 \\
\hline DESCRITORES IBICT & Dissertação & Tese & Total & Relação/tema \\
\hline $\begin{array}{l}\text { "Atuação docente" + "Educação de } \\
\text { Jovens e Adultos" }\end{array}$ & 42 & 11 & 53 & 04 \\
\hline
\end{tabular}




\section{ATUAÇÃO DOCENTE NA EDUCAÇÃO DE JOVENS E ADULTOS}

"Atuação docente na Educação de Jovens e Adultos"

01

00

01

01

Fonte: dados coletados no Banco de Teses e Dissertações da CAPES e IBICT, jan./2020. Elaboração dos autores.

\subsection{Políticas educacionais para Educação de Jovens e Adultos: levantamento quantitativo}

Quadro 3 - Políticas educacionais para Educação de Jovens e Adultos

\begin{tabular}{|c|c|c|c|c|}
\hline \multicolumn{5}{|c|}{ POLÍTICAS EDUCACIONAIS PARA EDUCAÇÃO DE JOVENS E ADULTOS } \\
\hline DESCRITORES CAPES & Dissertação & Tese & Total & Relação/tema \\
\hline $\begin{array}{l}\text { "Políticas educacionais para } \\
\text { Educação de Jovens e Adultos" }\end{array}$ & 71 & 33 & 104 & 02 \\
\hline $\begin{array}{l}\text { "Políticas educacionais" AND } \\
\text { "Educação de Jovens e Adultos" }\end{array}$ & 23 & 14 & 37 & 01 \\
\hline DESCRITORES IBICT & Dissertação & Tese & Total & Relação/tema \\
\hline $\begin{array}{c}\text { "Políticas educacionais" + } \\
\text { "Educação de Jovens e Adultos" }\end{array}$ & 03 & 04 & 07 & 04 \\
\hline $\begin{array}{l}\text { "Políticas educacionais para } \\
\text { Educação de Jovens e Adultos" }\end{array}$ & 04 & 05 & 09 & 03 \\
\hline
\end{tabular}

Fonte: dados coletados no Banco de Teses e Dissertações da CAPES e IBICT, jan./2020. Elaboração dos autores.

Inicialmente, as produções na CAPES e no IBICT foram localizadas por conterem em seus títulos o termo de busca definido. Posteriormente, fora realizada a leitura dos resumos, metodologias e referências, o que possibilitou identificar as informações sobre os objetivos das pesquisas. Quando, em alguns casos, essas informações não apareciam de forma clara, era necessária a leitura do trabalho inteiro para identificar as informações desejadas.

Os dados expostos nas tabelas acima já foram inseridos após a utilização de filtros operacionais de pesquisa. Ao se utilizarem as pesquisas sem a aplicação de nenhum tipo de filtro, na CAPES, totalizaram-se 3.605 produções, em que o primeiro descritor apresentava o total de 1.416 produções; o segundo, 1.349; e o terceiro descritor, 840 produções, divididas entre teses e dissertações. No IBICT, 
somou-se o total de 643 produções sem aplicação de filtros, contabilizados por 317 no primeiro descritor, 80 no segundo e 246 no terceiro, respectivamente.

A utilização dos filtros é importante por possibilitar ao pesquisador definir as pesquisas que mais se aproximam do seu objeto de estudo; sem a aplicação desses, encontramos produções de diversas áreas, como Saúde, Educação Especial, Educação do Campo, entre outras, que, apesar de serem importantes pesquisas, fogem do objeto de dissertação da pesquisadora.

Observando os descritores no que diz respeito ao recorte temporal definido e, após a aplicação de filtros, os trabalhos publicados entre os anos de 2008 e 2018, depois da triagem, conseguimos levantar no site da CAPES, com a soma dos três descritores, 374 publicações. O primeiro descritor contabilizava o total de 129 produções; o segundo, 104; e o terceiro, 141, conforme exposto no quadro a seguir.

Neste trabalho de estado do conhecimento, no recorte temporal estabelecido (2008-2012), sobretudo quando observada a quantidade da produção nos anos compreendidos entre 2008 e 2012 no banco de dados da CAPES, conforme exposto na Tabela 4, é importante destacar que ainda era pouco expressivo o número de iniciativas voltadas para a pesquisa da formação docente, atuação docente e políticas públicas docente na EJA, mesmo apresentando uma crescente quantidade de trabalhos nos anos posteriores. Podemos observar que são limitadas as contribuições que discutem a temática da formação docente com enfoque na modalidade EJA.

Quadro 4 - Dados quantitativos CAPES 2008-2018

\begin{tabular}{|c|c|c|c|c|c|c|c|c|c|c|c|}
\hline \multicolumn{10}{|c|}{ Descritor 1: Formação docente do educador de jovens e adultos } \\
\hline 2008 & 2009 & 2010 & 2011 & 2012 & 2013 & 2014 & 2015 & 2016 & 2017 & 2018 \\
\hline 07 & 14 & 00 & 00 & 00 & 23 & 18 & 15 & 11 & 22 & 19 \\
\hline \multicolumn{8}{|c|}{ Descritor 2: Atuação docente na Educação de Jovens e Adultos } \\
\hline 2008 & 2009 & 2010 & 2011 & 2012 & 2013 & 2014 & 2015 & 2016 & 2017 & 2018 \\
\hline 00 & 00 & 00 & 00 & 00 & 26 & 15 & 25 & 20 & 12 & 06 \\
\hline \multicolumn{1}{|c|}{ Descritor 3: Políticas educacionais para Educação de Jovens e Adultos } \\
\hline 2008 & 2009 & 2010 & 2011 & 2012 & 2013 & 2014 & 2015 & 2016 & 2017 & 2018 \\
\hline 10 & 14 & 00 & 00 & 00 & 22 & 20 & 22 & 17 & 16 & 20 \\
\hline
\end{tabular}

Fonte: dados coletados no Banco de Teses e Dissertações da CAPES, jan./2020. Elaboração dos autores. 
Dando sequência à pesquisa qualitativa, analisando agora as publicações na BDTD vendo o quantitativo das produções acadêmicas com o recorte temporal estabelecido, utilizando os mesmos descritores da CAPES, pode-se contabilizar no recorte temporal, após a aplicação de filtros, que o levantamento com a soma dos três descritores foi de 167 publicações. O primeiro descritor contabilizava o total de 97 produções; o segundo, 54; e o terceiro, 16.

Diante da produção acadêmica na BDTD, a totalidade dos estudos que atendiam aos critérios preestabelecidos era semelhante à da CAPES. E, tendo esses resultados como pressuposto, ratifica-se que a produção sobre os descritores já mencionados acima, no âmbito acadêmico, ainda é pequena; sobretudo quando comparada aos resultados da CAPES, podemos ver que a maioria dos anos analisados apresenta estudos. Mas, principalmente, não se pode associar a ausência da temática na produção acadêmica aos seus resultados, pois estes são inegáveis no contexto em que se legitima a ciência, contemplando a sua forma teórico-metodológica de análise. Os dados quantitativos encontrados podem ser vistos no Quadro 5, exibido a seguir.

Quadro 5 - Dados quantitativos BDTD 2008-2018

\begin{tabular}{|c|c|c|c|c|c|c|c|c|c|c|c|}
\hline \multicolumn{10}{|c|}{ Descritor 1: Formação docente do educador de jovens e adultos } \\
\hline 2008 & 2009 & 2010 & 2011 & 2012 & 2013 & 2014 & 2015 & 2016 & 2017 & 2018 \\
\hline 07 & 09 & 14 & 08 & 11 & 08 & 06 & 09 & 06 & 09 & 10 \\
\hline \multicolumn{8}{|c|}{ Descritor 2: Atuação docente na Educação de Jovens e Adultos } \\
\hline 2008 & 2009 & 2010 & 2011 & 2012 & 2013 & 2014 & 2015 & 2016 & 2017 & 2018 \\
\hline 06 & 02 & 04 & 07 & 05 & 01 & 02 & 02 & 07 & 08 & 09 \\
\hline \multicolumn{8}{|c|}{ Descritor 3: Políticas educacionais para Educação de Jovens e Adultos } \\
\hline 2008 & 2009 & 2010 & 2011 & 2012 & 2013 & 2014 & 2015 & 2016 & 2017 & 2018 \\
\hline 02 & 03 & 02 & 03 & 00 & 02 & 00 & 02 & 00 & 01 & 01 \\
\hline
\end{tabular}

Fonte: dados coletados no Banco de Teses e Dissertações da BTDT, jan./2020. Elaboração dos autores.

Fazendo uma análise geográfica das produções somando os três descritores, podemos concluir que, no recorte temporal e nos filtros aplicados, a CAPES concentra a maior parte de suas produções na região Nordeste, 149; seguida da região Sudeste, com 140; e Sul, com 85 produções. Já no IBICT, as produções se concentram na região Sudeste, 67; seguida pela região Nordeste, 63; Centro-Oeste, 
24; e região Sul, 14. Juntando os dois bancos de dados, as pesquisas totalizam por regiões em 1 10 lugar: a região Nordeste, com 212 produções; seguida da região Sudeste, com 207; Sul, com 99; e Centro-Oeste, com 24 produções. Essas pesquisas foram produzidas, em sua maioria, nas instituições públicas federais e estaduais.

As pesquisas produzidas demonstram um decréscimo na área de Políticas Públicas Educacionais nas regiões Norte, Sul e Centro-Oeste. A combinação entre as duas plataformas de pesquisa nas regiões e no espaço temporal de análise resultou em uma nítida tendência de ampliação das pesquisas na região Nordeste, destacando os Estados da Bahia, Paraíba e Rio Grande do Norte.

A seguir, apresentamos duas tabelas com dados das produções selecionadas nas plataformas CAPES e IBICIT:

Quadro 6 - Seleção das produções analisadas na CAPES

\begin{tabular}{|c|c|c|c|c|c|}
\hline Tipo & Produção & Autor & Ano & Instituição & Região \\
\hline 1. Diss. & $\begin{array}{l}\text { A prática do planejamento } \\
\text { de ensino na educação de } \\
\text { jovens e adultos }\end{array}$ & $\begin{array}{l}\text { NASCIMENTO, } \\
\text { João Maria P. } \\
\text { do }\end{array}$ & 2010 & UFPB & Nordeste \\
\hline 2. Diss. & $\begin{array}{l}\text { Saberes construídos pelos } \\
\text { professores nas práticas } \\
\text { docentes da educação de } \\
\text { jovens e adultos }\end{array}$ & $\begin{array}{l}\text { JÚNIOR, } \\
\text { Adenilson } \\
\text { Souza Cunha }\end{array}$ & 2012 & UFS & Nordeste \\
\hline 3. Diss. & $\begin{array}{l}\text { Educação de jovens e } \\
\text { adultos: uma reflexão sobre } \\
\text { os saberes escolares e } \\
\text { cotidianidade }\end{array}$ & $\begin{array}{l}\text { BEZERRA, } \\
\text { Andrezza } \\
\text { Raquel Cirne }\end{array}$ & 2013 & UFPB & Nordeste \\
\hline 4. Diss. & $\begin{array}{l}\text { O enunciado da educação } \\
\text { de jovens e adultos no curso } \\
\text { de pedagogia da ufpb/ } \\
\text { campus i }\end{array}$ & $\begin{array}{l}\text { ALCANTARA, } \\
\text { Marcos } \\
\text { Angelus } \\
\text { Miranda de }\end{array}$ & 2013 & UFPB & Nordeste \\
\hline 5. Diss. & $\begin{array}{l}\text { Alfabetização de Jovens } \\
\text { e Adultos no Estado da } \\
\text { Paraíba: uma análise político- } \\
\text { pedagógica das experiências } \\
\text { da campanha de Educação } \\
\text { Popular-CEPLAR }\end{array}$ & $\begin{array}{l}\text { FAÇANHA, } \\
\text { Sabrina Carla } \\
\text { Mateus }\end{array}$ & 2013 & UFPB & Nordeste \\
\hline
\end{tabular}




\begin{tabular}{|c|c|c|c|c|c|}
\hline Tipo & Produção & Autor & Ano & Instituição & Região \\
\hline 6. Diss. & $\begin{array}{l}\text { Políticas de formação do } \\
\text { pedagogo para atuação em } \\
\text { espaços não escolares: o } \\
\text { projeto político pedagógico } \\
\text { da autarquia municipal do } \\
\text { Ensino Superior de Goiana- } \\
\text { PE }\end{array}$ & $\begin{array}{l}\text { CABRAL, } \\
\text { Angela Ninfa } \\
\text { Mendes de } \\
\text { Andrade }\end{array}$ & 2013 & UFPB & Nordeste \\
\hline 7. Diss. & $\begin{array}{l}\text { Políticas públicas para a } \\
\text { Educação Profissional: } \\
\text { estudo da formação/ } \\
\text { profissionalização e do } \\
\text { trabalho do professor } \\
\text { do programa especial de } \\
\text { formação pedagógica de } \\
\text { docentes }\end{array}$ & $\begin{array}{l}\text { FARIA, } \\
\text { Vanessa } \\
\text { Piedade } \\
\text { Gontijo }\end{array}$ & 2014 & PUC-MG & Sudeste \\
\hline 8. Diss. & $\begin{array}{l}\text { Olhares atentos, detalhes } \\
\text { orientadores: o lugar da } \\
\text { inteligência popular na } \\
\text { Alfabetização de Jovens e } \\
\text { Adultos }\end{array}$ & $\begin{array}{l}\text { MELO, Elma } \\
\text { Nunes de }\end{array}$ & 2015 & UFPB & Nordeste \\
\hline 9. Diss. & $\begin{array}{l}\text { Histórias de vida: percursos } \\
\text { de formação de licenciados } \\
\text { em pedagogia no campo da } \\
\text { EJA }\end{array}$ & $\begin{array}{l}\text { MASSENA, } \\
\text { Renata da } \\
\text { Silva }\end{array}$ & 2015 & UNEB & Nordeste \\
\hline 10. Diss. & $\begin{array}{l}\text { A dor e a delícia de } \\
\text { tornar-se... Professor da } \\
\text { EJA: narrativas de si na } \\
\text { construção formativa de } \\
\text { educadores do juvenil do } \\
\text { município de Catu-BA }\end{array}$ & $\begin{array}{l}\text { ARAÚJO, } \\
\text { Margareth } \\
\text { da Conceição } \\
\text { Almeida de }\end{array}$ & 2015 & UNEB & Nordeste \\
\hline 11. Diss. & $\begin{array}{l}\text { Estudo dos saberes da } \\
\text { experiência docente no } \\
\text { contexto da Educação de } \\
\text { Jovens e Adultos }\end{array}$ & $\begin{array}{l}\text { SILVA, } \\
\text { Alexandre } \\
\text { Alves da }\end{array}$ & 2016 & UESB & Nordeste \\
\hline 12. Diss. & $\begin{array}{l}\text { A formação docente e o } \\
\text { fenômeno da na Educação } \\
\text { de Jovens e Adultos: } \\
\text { desafios formativos }\end{array}$ & $\begin{array}{l}\text { MACEDO, } \\
\text { Nubia Sueli } \\
\text { Silva }\end{array}$ & 2017 & UNEB & Nordeste \\
\hline
\end{tabular}




\begin{tabular}{|c|c|c|c|c|c|}
\hline Tipo & Produção & Autor & Ano & Instituição & Região \\
\hline 13. Diss. & $\begin{array}{l}\text { Formação de professor } \\
\text { da educação de jovens e } \\
\text { adultos: um olhar reflexivo } \\
\text { sobre os saberes docentes } \\
\text { em uma escola estadual } \\
\text { no município de Itamaraju- } \\
\text { Bahia }\end{array}$ & $\begin{array}{l}\text { SANTOS, } \\
\text { Maria } \\
\text { Madalena da } \\
\text { Conceição }\end{array}$ & 2017 & UNEB & Nordeste \\
\hline 14. Diss. & $\begin{array}{l}\text { Análise das práticas } \\
\text { pedagógicas dos professores } \\
\text { da EJA, à luz das políticas } \\
\text { educacionais em um } \\
\text { contexto sociocultural }\end{array}$ & $\begin{array}{l}\text { SANTOS, } \\
\text { Priscila } \\
\text { Morgana } \\
\text { Galdino dos }\end{array}$ & 2018 & UFPB & Nordeste \\
\hline 15. Diss. & $\begin{array}{l}\text { Narrativas (auto)biográficas } \\
\text { e formação de professores: } \\
\text { tessituras sobre as } \\
\text { trajetórias formativas de } \\
\text { professoras da Educação de } \\
\text { Jovens e Adultos }\end{array}$ & $\begin{array}{l}\text { CARDOSO, } \\
\text { Jackeline Silva }\end{array}$ & 2018 & UNEB & Nordeste \\
\hline 16. Diss. & $\begin{array}{l}\text { Políticas públicas de EJA no } \\
\text { município de Souto Soares- } \\
\text { Bahia: uma luta colaborativa } \\
\text { pela continuidade dos } \\
\text { estudos de Jovens e Adultos } \\
\text { no âmbito da Educação } \\
\text { Básica }\end{array}$ & $\begin{array}{l}\text { BISPO, Sonia } \\
\text { Vieira de } \\
\text { Souza }\end{array}$ & 2018 & UNEB & Nordeste \\
\hline 17. Diss. & $\begin{array}{l}\text { A formação inicial do curso } \\
\text { de Pedagogia da FE/UERN } \\
\text { para atuar na EJA }\end{array}$ & $\begin{array}{l}\text { SOARES, Maria } \\
\text { Cleoneide }\end{array}$ & 2018 & UERN & Nordeste \\
\hline 18. Tese & $\begin{array}{l}\text { Razão e formação } \\
\text { docente: uma análise das } \\
\text { racionalidades subjacentes } \\
\text { às políticas de formação } \\
\text { docente pós-LDB/96 }\end{array}$ & $\begin{array}{l}\text { FONSECA, } \\
\text { Fábio do } \\
\text { Nascimento }\end{array}$ & 2008 & UFPB & Nordeste \\
\hline
\end{tabular}




\begin{tabular}{|c|c|c|c|c|c|}
\hline Tipo & Produção & Autor & Ano & Instituição & Região \\
\hline 19. Tese & $\begin{array}{l}\text { Educação de Jovens e } \\
\text { Adultos nas vozes dos } \\
\text { sujeitos do campo no Pará: } \\
\text { da lógica de compensação } \\
\text { às perspectivas } \\
\text { emancipatórias }\end{array}$ & $\begin{array}{l}\text { NASCIMENTO, } \\
\text { Eula Regina } \\
\text { Lima }\end{array}$ & 2014 & UFPB & Nordeste \\
\hline 20. Tese & $\begin{array}{l}\text { Trajetórias formativas de } \\
\text { educadores da EJA: fios e } \\
\text { desafios' }\end{array}$ & $\begin{array}{l}\text { PEDROSO, Ana } \\
\text { Paula Ferreira }\end{array}$ & 2015 & UFMG & Sudeste \\
\hline 21. Tese & $\begin{array}{l}\text { A avaliação formativa } \\
\text { como regulação da } \\
\text { aprendizagem: desafios para } \\
\text { a práxis no ensino médio } \\
\text { da rede pública estadual } \\
\text { do Ceará em uma análise } \\
\text { fenomenológica }\end{array}$ & $\begin{array}{l}\text { OLIVEIRA, } \\
\text { Sandra Maria } \\
\text { Coelho de }\end{array}$ & 2015 & UFC & Nordeste \\
\hline 22.Tese & $\begin{array}{l}\text { Formação de professores } \\
\text { para a educação de pessoas } \\
\text { jovens e adultas no brasil } \\
\text { e no Chile: um estudo } \\
\text { comparado entre o estado } \\
\text { da Bahia e a região de } \\
\text { Valparaíso }\end{array}$ & $\begin{array}{l}\text { CUNHA } \\
\text { JÚNIOR, } \\
\text { Adenilson } \\
\text { Souza }\end{array}$ & 2017 & UFMG & Sudeste \\
\hline
\end{tabular}

Fonte: dados coletados nas pesquisas realizadas no Banco de Teses e Dissertações da CAPES, jan./2020. Elaboração da autora.

Quadro 7 - Seleção das produções analisadas no IBICT

\begin{tabular}{|c|l|l|l|l|l|}
\hline Tipo & \multicolumn{1}{|c|}{ Produção } & \multicolumn{1}{|c|}{ Autor } & Ano & Instituição & Região \\
1. Diss. & $\begin{array}{l}\text { A alfabetização sob o olhar } \\
\text { de uma educadora de EJA: } \\
\text { entre o como e o por quê }\end{array}$ & $\begin{array}{l}\text { Andréia da } \\
\text { Silva }\end{array}$ & 2008 & UNESP & Sudeste \\
\hline $\begin{array}{l}\text { 2. Diss. } \\
\begin{array}{l}\text { Trajetórias de educadores } \\
\text { construídas na Educação } \\
\text { de Jovens e Adultos: } \\
\text { experiências e significados }\end{array}\end{array} \begin{array}{l}\text { MATI, } \\
\text { Emmeline } \\
\text { Salume }\end{array}$ & 2008 & UFMG & Sudeste \\
\hline
\end{tabular}




\begin{tabular}{|c|c|c|c|c|c|}
\hline Tipo & Produção & Autor & Ano & Instituição & Região \\
\hline 3. Diss. & $\begin{array}{l}\text { Formação docente na } \\
\text { educação de jovens e } \\
\text { adultos: processo de } \\
\text { inclusão/exclusão de } \\
\text { pessoas com necessidades } \\
\text { educacionais especiais } \\
\text { em uma perspectiva de } \\
\text { humanização }\end{array}$ & $\begin{array}{l}\text { LINS, Vanira } \\
\text { Maria } \\
\text { Laranjeiras }\end{array}$ & 2008 & UFPE & Nordeste \\
\hline 4. Diss. & $\begin{array}{l}\text { A noção de competência } \\
\text { na política pública de } \\
\text { Educação de Jovens e } \\
\text { Adultos da rede municipal } \\
\text { de Betim: avanço e ou } \\
\text { retrocesso na formação } \\
\text { humana }\end{array}$ & $\begin{array}{l}\text { BITENCOURT, } \\
\text { Celeste } \\
\text { Deográcias de } \\
\text { Souza }\end{array}$ & 2009 & UERJ & Sudeste \\
\hline 5. Diss. & $\begin{array}{l}\text { Os desafios da formação } \\
\text { continuada de docentes } \\
\text { para atuação na Educação } \\
\text { Profissional articulada } \\
\text { à Educação de Jovens e } \\
\text { Adultos }\end{array}$ & $\begin{array}{l}\text { BONFIM, } \\
\text { Cristiane Jorge } \\
\text { de Lima }\end{array}$ & 2011 & UNB & $\begin{array}{l}\text { Centro- } \\
\text { Oeste }\end{array}$ \\
\hline 6. Diss. & $\begin{array}{l}\text { A formação do trabalho } \\
\text { docente: um estudo das } \\
\text { teorizações acerca das } \\
\text { dimensões pessoais no } \\
\text { exercício da profissão }\end{array}$ & $\begin{array}{l}\text { SILVA, Juliana } \\
\text { de Souza }\end{array}$ & 2012 & USP & Sudeste \\
\hline 7. Diss. & $\begin{array}{l}\text { Educação de Jovens e } \\
\text { Adultos na rede municipal } \\
\text { de São Paulo: diálogos } \\
\text { entre as políticas públicas } \\
\text { as práticas docentes e } \\
\text { seus significados }\end{array}$ & $\begin{array}{l}\text { SILVA, Robson } \\
\text { Novaes da }\end{array}$ & 2013 & USP & Sudeste \\
\hline 8. Diss. & $\begin{array}{l}\text { A política pública do } \\
\text { Estado de Mato Grosso } \\
\text { para a Educação de Jovens } \\
\text { e Adultos e o trabalho dos } \\
\text { professores formadores } \\
\text { da EJA }\end{array}$ & $\begin{array}{l}\text { SANTOS, Savio } \\
\text { Antunes dos }\end{array}$ & 2013 & UFMT & $\begin{array}{l}\text { Centro- } \\
\text { Oeste }\end{array}$ \\
\hline
\end{tabular}




\begin{tabular}{|c|c|c|c|c|c|}
\hline Tipo & Produção & Autor & Ano & Instituição & Região \\
\hline 9. Diss. & $\begin{array}{l}\text { A política de Educação } \\
\text { Municipal e o tratamento } \\
\text { da Educação de Jovens e } \\
\text { Adultos }\end{array}$ & $\begin{array}{l}\text { NAZÁRIO, } \\
\text { Marcia Aurelia }\end{array}$ & 2014 & UFPE & Nordeste \\
\hline 10. Diss. & $\begin{array}{l}\text { Práticas pedagógicas na } \\
\text { Educação de Jovens e } \\
\text { Adultos (EJA): interfaces } \\
\text { com as políticas e } \\
\text { diretrizes curriculares }\end{array}$ & $\begin{array}{l}\text { VELOSO, Zelia } \\
\text { Vieira Cruz }\end{array}$ & 2014 & PUC-GO & $\begin{array}{l}\text { Centro- } \\
\text { Oeste }\end{array}$ \\
\hline 11. Diss. & $\begin{array}{l}\text { O processo de formação } \\
\text { inicial de professores } \\
\text { dos anos iniciais da } \\
\text { EJA: uma análise do } \\
\text { curso de pedagogia de } \\
\text { Universidades Estaduais } \\
\text { de São Paulo }\end{array}$ & $\begin{array}{l}\text { FARIAS, } \\
\text { Alessandra } \\
\text { Fonseca }\end{array}$ & 2016 & UNESP & Sudeste \\
\hline 12. Diss. & $\begin{array}{l}\text { Concepções de qualidade } \\
\text { na Educação de Jovens } \\
\text { e Adultos: impasses } \\
\text { e desafios da política } \\
\text { educacional brasileira }\end{array}$ & $\begin{array}{l}\text { COUTINHO, } \\
\text { Helen Ferreira } \\
\text { Carvalho }\end{array}$ & 2016 & UFJF & Sudeste \\
\hline 13. Diss. & $\begin{array}{l}\text { O educador de jovens e } \\
\text { adultos e sua formação na } \\
\text { faculdade de educação da } \\
\text { Universidade Federal de } \\
\text { Minas Gerais }\end{array}$ & $\begin{array}{l}\text { SILVA-SOARES, } \\
\text { Rafaela Carla e }\end{array}$ & 2017 & UFMG & Sudeste \\
\hline 14. Diss. & $\begin{array}{l}\text { Da formação inicial à } \\
\text { continuada para a EJA: } \\
\text { desafios e implicações } \\
\text { para a prática docente }\end{array}$ & $\begin{array}{l}\text { ALVES, } \\
\text { Caroline Diniz } \\
\text { Nóbrega }\end{array}$ & 2018 & UEPB & Nordeste \\
\hline 15. Diss. & $\begin{array}{l}\text { A educação permanente } \\
\text { e sua interface com as } \\
\text { políticas educacionais } \\
\text { para Educação de Jovens, } \\
\text { Adultos e idosos no Brasil }\end{array}$ & $\begin{array}{l}\text { ALMEIDA, } \\
\text { Talita Costa de } \\
\text { Oliveira }\end{array}$ & 2018 & UEPG & Sul \\
\hline 16. Diss. & $\begin{array}{l}\text { Direito à Educação de } \\
\text { Jovens e Adultos na } \\
\text { tessitura das políticas } \\
\text { públicas de financiamento }\end{array}$ & $\begin{array}{l}\text { CARDOSO, } \\
\text { Caroline } \\
\text { Cristiano }\end{array}$ & 2018 & UFRGS & Sul \\
\hline
\end{tabular}




\begin{tabular}{|c|l|l|c|c|c|}
\hline Tipo & \multicolumn{1}{|c|}{ Produção } & \multicolumn{1}{|c|}{ Autor } & Ano & Instituição & Região \\
17. Tese & $\begin{array}{l}\text { Análise do conceito de } \\
\text { formação docente no } \\
\text { contexto educativo- } \\
\text { formativo brasileiro }\end{array}$ & $\begin{array}{l}\text { VIRGINIO, } \\
\text { Maria Helena } \\
\text { da Silva }\end{array}$ & 2009 & UFPB & Nordeste \\
18. Tese & $\begin{array}{l}\text { Trajetórias e processos } \\
\text { formativos na/da } \\
\text { docência: memórias e } \\
\text { [res]significações }\end{array}$ & $\begin{array}{l}\text { MARQUEZAN, } \\
\text { Lorena Inês } \\
\text { Peterini }\end{array}$ & 2015 & UFSM & Sul \\
\hline 19. Tese & $\begin{array}{l}\text { Caminhos e desafios da } \\
\text { formação de educadores } \\
\text { de jovens e adultos }\end{array}$ & $\begin{array}{l}\text { PORCARO, } \\
\text { Rosa Cristina }\end{array}$ & 2015 & UFMG & Sudeste \\
\hline
\end{tabular}

Fonte: dados coletados nas pesquisas realizadas no Banco de Teses e Dissertações da IBICT, Jan./2020. Elaboração dos autores.

\section{COLETA DE DADOS DA ANPAE E DA ANPED}

Nos anais dos simpósios nacionais da Associação Nacional de Política e Administração da Educação (ANPAE), as pesquisas foram realizadas entre os anos de 2009 e 2017. Uma vez que as reuniões nacionais ocorrem bianualmente, foram analisados, ao todo, 48 trabalhos. Na Associação Nacional de Pós-Graduação e Pesquisa em Educação (ANPED), as pesquisas se dividiram por grupos de trabalhos (GTs) e foram analisadas 78 produções presentes nos GTs: 18 (Educação de Pessoas Jovens e Adultas), 08 (Formação de Professores) e 06 (Educação Popular). Ao todo, foram reunidos 30 trabalhos, dos quais 23 foram selecionados para estudo, sendo, desses, 15 produções da ANPED e 08 produções da ANPAE.

Quadro 8 - Produções da ANPAE

\begin{tabular}{|c|l|c|c|c|c|}
\hline $\begin{array}{c}\text { Produção } \\
\text { acadêmica }\end{array}$ & \multicolumn{1}{|c|}{ Produção } & Autor & Ano & Instituição & Região \\
\begin{tabular}{|l} 
Educação de Jovens e \\
$\begin{array}{l}\text { 1. ANPAE } \\
\mathbf{X X V I}\end{array}$
\end{tabular} & $\begin{array}{l}\text { Adultos em Ponta Grossa: } \\
\text { entre políticas } \\
\text { públicas e a realidade } \\
\text { docente }\end{array}$ & $\begin{array}{l}\text { SILVA, Rita } \\
\text { de Cássia da } \\
\text { Oliveira }\end{array}$ & 2009 & UFES & Nordeste \\
\hline
\end{tabular}




\begin{tabular}{|c|c|c|c|c|c|}
\hline $\begin{array}{l}\text { Produção } \\
\text { acadêmica }\end{array}$ & Produção & Autor & Ano & Instituição & Região \\
\hline $\begin{array}{l}\text { 2. ANPAE } \\
\text { XXVI }\end{array}$ & $\begin{array}{l}\text { A Educação de Jovens e } \\
\text { Adultos no plano nacional } \\
\text { de educação e nos planos } \\
\text { estaduais de educação }\end{array}$ & $\begin{array}{l}\text { MACHADO, } \\
\text { Maria } \\
\text { Margarida }\end{array}$ & 2009 & UFG & $\begin{array}{l}\text { Centro- } \\
\text { Oeste }\end{array}$ \\
\hline $\begin{array}{l}\text { 3. ANPAE } \\
\text { XXVI }\end{array}$ & $\begin{array}{l}\text { O processo histórico de } \\
\text { consolidação da Educação } \\
\text { de Jovens e Adultos: as } \\
\text { políticas públicas voltadas } \\
\text { para EJA e a luta dos } \\
\text { movimentos sociais para } \\
\text { a efetivação do direito a } \\
\text { educação }\end{array}$ & $\begin{array}{l}\text { SOUZA, } \\
\text { Thiana do } \\
\text { Eirado Sena } \\
\text { de }\end{array}$ & 2013 & UESB & Nordeste \\
\hline $\begin{array}{l}\text { 4. ANPAE } \\
\text { XXVI }\end{array}$ & $\begin{array}{l}\text { Concepções de cidadania: } \\
\text { tensões e intenções no } \\
\text { processo de escolarização } \\
\text { das pessoas jovens e } \\
\text { adultas }\end{array}$ & $\begin{array}{l}\text { RODRIGUES, } \\
\text { Luiz Rubens }\end{array}$ & 2015 & UFJF & Sudeste \\
\hline $\begin{array}{l}\text { 5. ANPAE } \\
\text { XXVI }\end{array}$ & $\begin{array}{l}\text { As perspectivas para a } \\
\text { Educação de Jovens e } \\
\text { Adultos a partir } \\
\text { do novo plano nacional de } \\
\text { educação }\end{array}$ & $\begin{array}{l}\text { FERNANDES, } \\
\text { Sandra Leite }\end{array}$ & 2015 & UNICAMP & Sudeste \\
\hline $\begin{array}{l}\text { 6. ANPAE } \\
\text { XXVI }\end{array}$ & $\begin{array}{l}\text { As políticas educacionais e } \\
\text { o programa nacional de } \\
\text { Educação Profissional } \\
\text { integrado à Educação } \\
\text { Básica na modalidade } \\
\text { Educação de Jovens e } \\
\text { Adultos }\end{array}$ & $\begin{array}{l}\text { BARACHO, } \\
\text { Maria das } \\
\text { Graças }\end{array}$ & 2015 & IFRN & Nordeste \\
\hline $\begin{array}{l}\text { 7. ANPAE } \\
\text { XXVI }\end{array}$ & $\begin{array}{l}\text { A formação profissional } \\
\text { para jovens e adultos: um } \\
\text { processo em construção? }\end{array}$ & $\begin{array}{l}\text { CABRAL } \\
\text { NETO, } \\
\text { Antônio }\end{array}$ & 2017 & UFRN & Nordeste \\
\hline $\begin{array}{l}\text { 8. ANPAE } \\
\text { XXVI }\end{array}$ & $\begin{array}{l}\text { Políticas públicas para } \\
\text { a Educação de Jovens } \\
\text { e Adultos no Brasil nos } \\
\text { últimos } 10 \text { (dez) anos: } \\
\text { desafios e potencialidades }\end{array}$ & $\begin{array}{l}\text { VELIS, } \\
\text { Valéria Ap. } \\
\text { Vieira }\end{array}$ & 2017 & UNESP & Sudeste \\
\hline
\end{tabular}

Fonte: dados coletados nas pesquisas realizadas na ANPAE 2020. Elaboração dos autores. 
Quadro 9 - Produções da ANPED

\begin{tabular}{|c|c|c|c|c|c|}
\hline $\begin{array}{l}\text { Produção } \\
\text { acadêmica }\end{array}$ & Produção & Autor & Ano & Instituição & Região \\
\hline $\begin{array}{l}\text { 1. Trabalho } \\
\text { ANPED } \\
\text { GT } 18\end{array}$ & $\begin{array}{l}\text { Formação de educadores } \\
\text { de jovens e adultos: } \\
\text { saberes na } \\
\text { proposição curricular }\end{array}$ & $\begin{array}{l}\text { PINHEIRO, } \\
\text { Rosa } \\
\text { Aparecida }\end{array}$ & 2008 & UFRN & Nordeste \\
\hline $\begin{array}{l}\text { 2. Trabalho } \\
\text { ANPED } \\
\text { GT } 18\end{array}$ & $\begin{array}{l}\text { O permanente } \\
\text { amadorismo em EJA: a } \\
\text { experiência da formação } \\
\text { de educadores em } \\
\text { educação de jovens e } \\
\text { adultos no município do } \\
\text { Rio de Janeiro }\end{array}$ & $\begin{array}{l}\text { RIBEIRO, Ana } \\
\text { Cristina }\end{array}$ & 2008 & UNESA, RJ & Sudeste \\
\hline $\begin{array}{l}\text { 3. Trabalho } \\
\text { ANPED } \\
\text { GT } 18\end{array}$ & $\begin{array}{l}\text { "A política dos outros" na } \\
\text { produção de sentidos } \\
\text { sobre formação de } \\
\text { professores de jovens e } \\
\text { adultos }\end{array}$ & $\begin{array}{l}\text { ALVARENGA, } \\
\text { Marcia Soares } \\
\text { de }\end{array}$ & 2009 & UERJ & Sudeste \\
\hline $\begin{array}{l}\text { 4. Trabalho } \\
\text { ANPED } \\
\text { GT } 08\end{array}$ & $\begin{array}{l}\text { Interdisciplinaridade e } \\
\text { inovação educativa pelo } \\
\text { olhar etnográfico }\end{array}$ & $\begin{array}{l}\text { PEREIRA, } \\
\text { Antonio } \\
\text { Serafim }\end{array}$ & 2010 & UNESC & Sul \\
\hline $\begin{array}{l}\text { 5. Trabalho } \\
\text { ANPED } \\
\text { GT } 18\end{array}$ & $\begin{array}{l}\text { Formação de professores } \\
\text { da Educação de Jovens e } \\
\text { Adultos: ensaio sobre a } \\
\text { possibilidade de diálogo } \\
\text { entre o conceito de } \\
\text { capital cultural e a crítica } \\
\text { à Educação Bancária }\end{array}$ & $\begin{array}{l}\text { SILVA, } \\
\text { Waldeck } \\
\text { Carneiro da }\end{array}$ & 2010 & UFF & Sudeste \\
\hline $\begin{array}{l}\text { 6. Trabalho } \\
\text { ANPED } \\
\text { GT } 08\end{array}$ & $\begin{array}{l}\text { Necessidades formativas } \\
\text { de educadores que atuam } \\
\text { em projetos de educação } \\
\text { não-formal }\end{array}$ & $\begin{array}{l}\text { PRÍNCEPE, } \\
\text { Lisandra } \\
\text { Marisa }\end{array}$ & 2011 & PUC-SP & Sudeste \\
\hline $\begin{array}{l}\text { 7. Trabalho } \\
\text { ANPED } \\
\text { GT } 08\end{array}$ & $\begin{array}{l}\text { A constituição dos } \\
\text { formadores de } \\
\text { professores } \\
\text { e a potencialidade da } \\
\text { práxis histórica de Paulo } \\
\text { Freire para estudos e } \\
\text { ações }\end{array}$ & $\begin{array}{l}\text { DE PAULA, } \\
\text { Lucimara } \\
\text { Cristina }\end{array}$ & 2011 & UFSCar & Sudeste \\
\hline
\end{tabular}




\begin{tabular}{|c|c|c|c|c|c|}
\hline $\begin{array}{l}\text { Produção } \\
\text { acadêmica }\end{array}$ & Produção & Autor & Ano & Instituição & Região \\
\hline $\begin{array}{l}\text { 8. Trabalho } \\
\text { ANPED } \\
\text { GT } 18\end{array}$ & $\begin{array}{l}\text { Caminhos e desafios à } \\
\text { formação de educadores } \\
\text { de jovens e adultos }\end{array}$ & $\begin{array}{l}\text { PORCARO, } \\
\text { Rosa Cristina }\end{array}$ & 2011 & $\begin{array}{l}\text { UFV } \\
\text { UFMG }\end{array}$ & Sudeste \\
\hline $\begin{array}{l}\text { 9. Trabalho } \\
\text { ANPED } \\
\text { GT } 18\end{array}$ & $\begin{array}{l}\text { A mediação na prática } \\
\text { pedagógica da Educação } \\
\text { de Jovens e Adultos: } \\
\text { sentidos e complexidades } \\
\text { imanentes }\end{array}$ & $\begin{array}{l}\text { LOSSO, } \\
\text { Adriana } \\
\text { Regina } \\
\text { Sanceverino }\end{array}$ & 2011 & UFFS, SC & Sul \\
\hline $\begin{array}{l}\text { 10. Trabalho } \\
\text { ANPED } \\
\text { GT } 08\end{array}$ & $\begin{array}{l}\text { A relação entre OCDE e } \\
\text { a política de formação } \\
\text { docente brasileira }\end{array}$ & $\begin{array}{l}\text { FERREIRA, } \\
\text { Diana Lemes }\end{array}$ & 2012 & UFPA & Norte \\
\hline $\begin{array}{l}\text { 11. Trabalho } \\
\text { ANPED } \\
\text { GT } 18\end{array}$ & $\begin{array}{l}\text { Pesquisas em Educação } \\
\text { de Jovens e Adultos no } \\
\text { Brasil: a presença de } \\
\text { Paulo Freire }\end{array}$ & $\begin{array}{l}\text { OLIVEIRA, } \\
\text { Ivanilde } \\
\text { Apoluceno de }\end{array}$ & 2012 & UEPA & Norte \\
\hline $\begin{array}{l}\text { 12. Trabalho } \\
\text { ANPED } \\
\text { GT } 18\end{array}$ & $\begin{array}{l}\text { "Educar servidores } \\
\text { públicos": dilemas da } \\
\text { docência no contexto de } \\
\text { trabalho da Educação de } \\
\text { Jovens e Adultos }\end{array}$ & $\begin{array}{l}\text { BANDEIRA, } \\
\text { Elça Maria Sá }\end{array}$ & 2012 & UECE & Nordeste \\
\hline $\begin{array}{l}\text { 13. Trabalho } \\
\text { ANPED } \\
\text { GT } 06\end{array}$ & $\begin{array}{l}\text { Educação popular como } \\
\text { política pública: análise } \\
\text { crítica }\end{array}$ & $\begin{array}{l}\text { SCHÖNARDIE, } \\
\text { Paulo Alfredo }\end{array}$ & 2015 & UNIJUÍ, RS & Sul \\
\hline $\begin{array}{l}\text { 14. Trabalho } \\
\text { ANPED } \\
\text { GT } 18\end{array}$ & $\begin{array}{l}\text { Construção da identidade } \\
\text { do docente da Educação } \\
\text { de Jovens e Adultos: } \\
\text { contribuições da prática } \\
\text { de ensino e da extensão } \\
\text { universitária }\end{array}$ & $\begin{array}{l}\text { MOURA, Ana } \\
\text { Paula Abreu }\end{array}$ & 2015 & UFRJ & Sudeste \\
\hline $\begin{array}{l}\text { 15. Trabalho } \\
\text { ANPED } \\
\text { GT } 18\end{array}$ & $\begin{array}{l}\text { Políticas de EJA } \\
\text { Implementadas nos } \\
\text { últimos } 20 \text { anos e uma } \\
\text { leitura no campo das } \\
\text { políticas do novo cenário }\end{array}$ & $\begin{array}{l}\text { MACHADO, } \\
\text { Maria } \\
\text { Margarida }\end{array}$ & 2017 & UFG & $\begin{array}{l}\text { Centro- } \\
\text { Oeste }\end{array}$ \\
\hline
\end{tabular}

Fonte: Dados coletados nas pesquisas realizada na ANPED, jan./2020. Elaboração dos autores. 
As pesquisas mostram que na ANPAE as produções classificadas estão concentradas, respectivamente, nas Regiões Nordeste, com 04 produções; Sudeste, 03 Produções; e Centro-Oeste, com 01 produção. Podemos observar que as pesquisas analisadas na ANPED se concentram nas regiões Sudeste, com 10 produções; Nordeste, 06 produções; Sul, 03 produções; e Centro-Oeste e Norte, com 02 produções, nessa ordem.

Machado (2000), ao estudar sobre a produção científica na área da EJA, mostra-nos que a vida profissional do docente dessa modalidade de ensino não possibilita sua formação continuada por meio de estudos ou de cursos e que, ainda, quando de alguma forma existe esse aperfeiçoamento, a formação recebida é insuficiente e inadequada para atender às demandas impostas pela maioria das instituições. A autora afirma que:

As pesquisas relacionadas à formação de professores também ressaltam em suas conclusões a necessidade de um processo de formação continuada, primando pela articulação entre teoria e prática, que inclua a superação da desarticulação entre as propostas pedagógicas de formação e os objetivos específicos da Educação de Jovens e Adultos, quer seja oferecida por secretarias de estado e municípios ou por universidades. (MACHADO, 2000, p. 24).

Segundo a autora, então, há uma fragilidade na formação desse professor, que acaba por ter de aprender junto dos alunos, gerando, assim, dificuldades em praticar os princípios político-pedagógicos defendidos pela EJA - situação ainda vista e vivenciada nos dias atuais.

\section{ALGUMAS CONSIDERAÇÕES}

O que podemos constatar com as pesquisas é que o Brasil está vivendo, ainda, um momento de configuração e renovação do processo de formação do educador de jovens e adultos, visto que essa realidade demanda muita discussão sobre o processo de ensino na EJA e, mais especificamente, sobre o processo de formação desses educadores.

Em relação às regiões geográficas brasileiras, todas as cinco produziram pesquisas analisadas neste estudo, totalizando 559 produções. A concentração dos programas de pós-graduação brasileiros na Região Nordeste fez esta região contribuir com 39,71\% do total de pesquisas; seguida pela região Sudeste, com 39,36\%; Sul, com 15,74\%. As regiões Centro-Oeste e Norte ficaram com menos 
de $10 \%$ das pesquisas, 4,83\% e 0,35\%, respectivamente. A produção de pesquisas na área de Educação parece demonstrar a fragilidade das políticas públicas de Educação nas regiões brasileiras que são economicamente mais carentes.

Analisar e coletar dados sobre as características da produção acadêmica de determinada área do conhecimento exige que o pesquisador estabeleça critérios analíticos, de modo a coletar dados que tenham relevância para o pesquisador, mostrando um balanço e uma análise sistematizada do desenvolvimento do campo do conhecimento sugerido.

São diversas as pesquisas que analisam a relação entre formação docente, atuação docente e políticas públicas na EJA. Para essas pesquisas, a EJA consistiria em uma forma de os educadores se prepararem quanto ao saber para a participação na vivência em comunidade ou a organização social de acordo com seu percurso formativo ao longo da vida.

Notamos que essa discussão ainda pode ser mais explorada, sobretudo na dimensão das políticas públicas. Algumas pesquisas descreveram como a EJA, entendida das mais variadas formas, seja como formação, atuação ou políticas públicas, pode assegurar o sucesso dos projetos de escolarização de jovens e adultos.

Por fim, o conjunto das pesquisas sobre a temática exposta aqui demonstra muitas limitações para conclusões mais consistentes. Os números encontrados nesta pesquisa demonstram que o tema da EJA tem sua importância dentro do campo da produção científica na área da educação. Mas há de se notar, no entanto, um maior interesse da área em pesquisas educacionais que relacionam a EJA com as áreas de letramento, memórias, Linguística, Geografia e Matemática, apontando a necessidade de se expandirem os estudos e as pesquisas no campo das políticas públicas, da trajetória e da formação docente.

\section{REFERÊNCIAS}

ALCANTARA, Marcos Angelus Miranda de. O enunciado da Educação de Jovens e Adultos no Curso de Pedagogia da UFPB/Campus I. 2013. 160 f. Dissertação (Mestrado em Educação) - Universidade Federal da Paraíba, João Pessoa, PB, 2013.

ASSOCIAÇÃO NACIONAL DE POLÍTICA E ADMINISTRAÇÃO DA EDUCAÇÃO [ANPAE], [s.d.] IN: SIMPÓSIO BRASILEIRO DE POLÍTICA E ADMINISTRAÇÃO DA EDUCAÇÃO. Disponível em https://anpae.org.br/website/simposios/simposios-historicos. Acesso: 22 jan. 2020 
ARAÚJO, Margareth da Conceição Almeida de. A dor e a delícia de tornar-se professor da EJA: narrativas de si na construção formativa de educadores do juvenil do município de Catu-BA. 2015. 125 f. Dissertação (Mestrado em Educação) - Universidade do Estado da Bahia, Salvador, BA, 2015.

BEZERRA, Andrezza Raquel Cirne. Educação de jovens e adultos: uma reflexão sobre a relação de saberes escolares e cotidianidades. 2013. 137 f. Dissertação (Mestrado em Educação) - Universidade Federal da Paraíba, João Pessoa, PB, 2013.

CABRAL, Angela Ninfa Mendes De Andrade. Políticas de formação do pedagogo para atuação em espaços não escolares: o projeto político pedagógico da Autarquia Municipal do Ensino Superior de Goiana-PE. 2013. Dissertação (Mestrado em Educação) Universidade Federal da Paraíba, João Pessoa, PB, 2013.

COORDENAÇÃO DE APERFEIÇOAMENTO DE PESSOAL DE NÍVEL SUPERIOR (CAPES). Mestrados e doutorados reconhecidos. Brasília-DF, 2020. Disponível em: https:// catalogodeteses.capes.gov.br/catalogo-teses/\#!/. Acesso em: 20 jan. 2020.

FAÇANHA, Sabrina Carla Mateus. Alfabetização de jovens e adultos no Estado da Paraíba: registros político-pedagógica de experiências da década de 1960. 2013. 104 f. Dissertação (Mestrado em Educação) - Universidade Federal da Paraíba, João Pessoa, PB, 2013.

FARIA, Vanessa Piedade Gontijo. Políticas públicas para a educação profissional: estudo da formação/profissionalização e do trabalho do professor do programa especial de formação pedagógica de docentes. 2014. 116 f. Dissertação (Mestrado em Educação) Pontifícia Universidade Católica de São Paulo, São Paulo, SP, 2014.

JÚNIOR, Adenilson Souza Cunha. Formação de professores para a educação de pessoas jovens e adultas no Brasil e no Chile: um estudo comparado entre o estado da Bahia e a região de Valparaíso. 2017. 227 f. Tese (Doutorado em Educação) - Universidade Federal de Minas Gerais, Belo Horizonte, MG, 2017.

MACEDO, Nubia Sueli Silva. A formação docente e o fenômeno da juvenilização na educação de jovens e adultos: desafios formativos. 2017. 139 f. Dissertação (Mestrado Profissional em Educação de Jovens e Adultos) - Universidade do Estado da Bahia, Salvador, BA, 2017.

MACHADO, M. M. A prática e a formação de professores na EJA: uma análise de dissertações e teses produzidas no período de 1986 a 1998. In: REUNIÃO ANUAL DA ANPED, 23, 2000, Associação Nacional de Pós-Graduação e Pesquisa em Educação, Caxambu, 2000. (Edição eletrônica). 
MASSENA, Renata da Silva. Histórias de vida: percursos de formação de licenciados em pedagogia no campo da EJA. 2015. 123 f. Dissertação (Mestrado Profissional em Educação de Jovens e Adultos) - Universidade do Estado da Bahia, Salvador, BA, 2015.

MATI, Emmeline Salume. Trajetórias de educadores construídas na educação de jovens e adultos: experiências e significados. 2008. 296 f. Dissertação (Mestrado em Educação) - Universidade Federal de Minas Gerais, Belo Horizonte, MG, 2008.

MELO, Elma Nunes de. Olhares atentos, detalhes orientadores: o lugar da inteligência popular na alfabetização de jovens e adultos. 2015. 154 f. Tese (Doutorado em Educação) - Universidade Federal da Paraíba, João Pessoa, PB, 2015.

NASCIMENTO, João Maria Pereira Do. A prática do planejamento de ensino na educação de jovens e adultos. 2010. 94 f. Dissertação (Mestrado em Educação) - Universidade Federal da Paraíba, João Pessoa, PB, 2010.

PEREIRA, Andréia da Silva. A alfabetização sob o olhar de uma educadora de EJA: entre o como e o por que. 2008. 105 f. Dissertação (Mestrado em Educação) - Universidade Estadual Paulista, Franca, SP, 2017.

SANTOS, Priscila Morgana Galdino dos. Análise das práticas pedagógicas dos professores da EJA, à luz das políticas educacionais em um contexto sociocultural. 2018. Dissertação (Mestrado em Educação) - Universidade do Estado da Bahia, Salvador, BA, 2018.

SANTOS, Maria Madalena da Conceição. Formação de professor da educação de jovens e adultos: um olhar reflexivo sobre os saberes docentes em uma escola estadual no município de Itamaraju-Bahia. 2017. 107 f. Dissertação (Mestrado Profissional em Educação de Jovens e Adultos) - Universidade do Estado da Bahia, Salvador, BA, 2017

SILVA, Alexandre Alves da. Estudo dos saberes da experiência docente no contexto da educação de jovens e adultos. 2016. Dissertação (Mestrado em Educação) - Universidade Estadual do Sudoeste da Bahia, Vitória da Conquista, BA, 2016.

SILVA-SOARES, Rafaela Carla. O educador de jovens e adultos e sua formação na Faculdade de Educação da Universidade Federal de Minas Gerais. 2017. Dissertação (Mestrado em Educação) - Universidade Federal de Minas Gerais, Belo Horizonte, MG, 2017.

SOARES, Magda Batista. Alfabetização no Brasil: o estado do conhecimento. Brasília: MEC/INEP/Reduc, 1989.

VOSGERAU, Dilmeire Sant'Anna Ramos; ROMANOWSKI, Joana Paulin. Estudos de Revisão: implicações conceituais e metodológicas. Revista Diálogo Educacional. Curitiba, v. 14, n. 41, p. 165-89, jan./abr. 2014. 


\section{Sobre os autores:}

Marileide Lima Moutinho Pamponet Lima: Mestre em Educação pelo Programa de Pós-Graduação em Educação da Universidade Estadual do Sudoeste da Bahia (UESB). Licenciada em Pedagogia pela Universidade Estadual do Sudoeste da Bahia. E-mail: leidemp@hotmail.com, Orcid: http://orcid.org/0000-0002-1688-6892

Adenilson Souza Cunha Júnior: Doutor em Educação pela Universidade Federal de Minas Gerais (UFMG). Mestre em Educação pela Universidade Federal de Sergipe (UFS). Licenciado em Pedagogia pela Universidade Estadual do Sudoeste da Bahia (UESB). Professor adjunto do Departamento de Ciências Humanas, Educação e Linguagem e do Programa de Pós-Graduação em Educação da Universidade Estadual do Sudoeste da Bahia (UESB). E-mail: adenilsoncunha@uesb.edu.br, Orcid: http://orcid.org/0000-0003-3622-1799

Recebido em: 10/03/2020

Aprovado em: 1\%/02/2021 
